Edubiotik: Jurnal Pendidikan, Biologi dan Terapan
ISSN 2528-679X (print), ISSN 2597-9833 (online)
Volume 5, Nomor 02, Tahun 2020, Hal. 114-122
Available online at:
http:/lejurnal.budiutomomalang.ac.id/index.php/edubiotik

Research Article

OPEN 2 ACCESS

\title{
Pengaruh penggunaan model read question answer terhadap keaktifan mahasiswa dalam berdiskusi pada mata kuliah mikologi
}

\author{
Farida Nurlaila Zunaidah ${ }^{*}$, Tutut Indah Sulistiyowati2 \\ ${ }^{1}$ Pendidikan Guru Sekolah Dasar, Universitas Nusantara PGRI Kediri, Kediri, Indonesia \\ 2Pendidikan Biologi, Universitas Nusantara PGRI Kediri, Kediri, Indonesia \\ Email: farida@unpkediri.ac.id*, tututindah.team@gmail.com
}

\begin{tabular}{|c|c|}
\hline Informasi Artikel & ABSTRACT \\
\hline $\begin{array}{l}\text { Submit: } 29-06-2020 \\
\text { Diterima: } 30-11-2020 \\
\text { Dipublikasikan: } 30-11-2020\end{array}$ & $\begin{array}{l}\text { The low activity of students in discussing mycology courses is caused by the lack } \\
\text { of use of innovative learning models. The research purpose was to determine the } \\
\text { effect of using the Read Question Answer (RQA) model on student activeness in } \\
\text { discussing mycology courses. This research uses quantitative research methods } \\
\text { with a quasi-experimental research type through a one-group pretest-posttest } \\
\text { research design. The research instrument used was a student activity } \\
\text { questionnaire. Research data is the average value of student activity. The } \\
\text { research data analysis technique used the dependent paired sample t-test. The } \\
\text { results showed that there was an effect of using the RQA model on student } \\
\text { activeness in discussing mycology courses. This is evident from the t-count value } \\
\text { is greater than the t-table (7.15> 2.23). The conclusion of this research is the use } \\
\text { of the RQA model affects student activeness in discussing mycology courses. } \\
\text { Key words: Activeness; mycology; RQA model }\end{array}$ \\
\hline Penerbit & ABSTRAK \\
\hline $\begin{array}{l}\text { Program Studi Pendidikan Biologi } \\
\text { IKIP Budi Utomo, Malang, Indonesia }\end{array}$ & $\begin{array}{l}\text { Rendahnya keaktifan mahasiswa dalam berdiskusi pada matakuliah mikologi } \\
\text { yang disebabkan oleh kurangnya penggunaan model pembelajaran inovatif. } \\
\text { Tujuan penelitian adalah untuk mengetahui pengaruh penggunaan model Read } \\
\text { Question Answer (RQA) terhadap keaktifan mahasiswa dalam berdiskusi pada } \\
\text { mata kuliah mikologi. Penelitian ini menggunakan metode penelitian kuantitatif } \\
\text { dengan jenis penelitian kuasi eksperimen melalui desain penelitian one group } \\
\text { pretest-posttest. Instrumen penelitian yang digunakan adalah angket keaktifan } \\
\text { mahasiswa. Data penelitian adalah nilai rata-rata keaktifan mahasiswa. Teknik }\end{array}$ \\
\hline 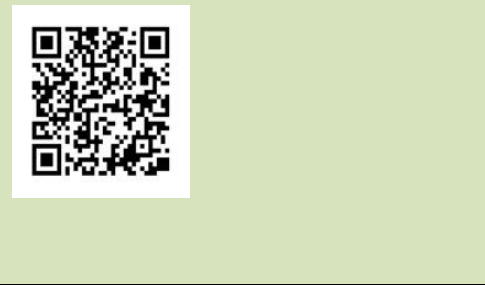 & $\begin{array}{l}\text { analisis data penelitian menggunakan dependent paired sampel t-test. Hasil } \\
\text { penelitian menunjukkan bahwa ada pengaruh penggunaan model RQA terhadap } \\
\text { keaktifan mahasiswa dalam berdiskusi pada mata kuliah mikologi. Hal tersebut } \\
\text { terbukti dari nilai t-hitung lebih besar dari t-tabel }(7,15>2,23) \text {. Simpulan } \\
\text { penelitian ini adalah penggunaan model RQA berpengaruh terhadap keaktifan } \\
\text { mahasiswa dalam berdiskusi pada mata kuliah mikologi. } \\
\text { Kata kunci: Keaktifan; mikologi; model RQA }\end{array}$ \\
\hline
\end{tabular}

This Edubiotik : Jurnal Pendidikan, Biologi dan Terapan is licensed under a CC BY-SA (Creative Commons AttributionShareAlike 4.0 International License)

\section{PENDAHULUAN}

Pada proses perkuliahan terdapat mata kuliah yang wajib ditempuh dan mata kuliah pilihan. Berdasarkan kurikulum KKNI yang digunakan dalam kegiatan perkuliahan tidak hanya menguasai materi yang ada, namun juga harus menguasai praktik yang ada dalam mata kuliah tersebut (Solikhah, 
2015). Mikologi merupakan mata kuliah yang wajib ditempuh oleh mahasiswa Program Studi Biologi semester 3 Universitas Nusantara PGRI Kediri. Mata kuliah mikologi ini mempelajari tentang berbagai macam karakteristik serta ciri-ciri dari jamur makroskopis maupun mikroskopis. Pelaksanaan mata kuliah mikologi terbagi atas dua sesi yakni teori dan praktik. Satu minggu ada dua jadwal yang berbeda pada mata kuliah mikologi ini. Hari pertama digunkan untuk menjelaskan materi yang akan dibahas perminggunya, kemudian hari kedua digunakan untuk kegiatan praktik bagi materi yang ada kegiatan praktiknya. Kegiatan praktik dilakukan dalam bentuk praktikum, dimana kegiatan praktikum yang dilaksanakan bertujuan untuk meningkatkan pemahaman mahasiswa terhadap materi yang sudah disampaikan sebelumnya. Adanya praktik di dalam perkuliahan mikologi dikarenakan banyaknya keunikan jamur makroskopis disekitar kita. Keunikan jamur makroskopis terlihat dari keberagaman jenis, bentuk dan habitatnya, sehingga perlu pengamatan lebih lanjut agar lebih memahaminya (Irianto, 2014).

Perkuliahan secara umum merupakan proses transfer ilmu antara dosen dan mahasiswa. Proses transfer ilmu melalui beberapa tahap antara lain tahap penjelasan materi, diskusi dan tanya jawab mengenai materi yang disampaika (Mahamod \& Mustapha, 2007). Tahapan tersebut merupakan bagian dari proses umpan balik antara dosen dengan mahasiswa agar suasana pembelajaran lebih aktif dan menarik (Hayu, 2017). Pada penelitian (Harlis \& Budiarti, 2017) diketahui bahwa dalam perkuliahan mikologi perlu adanya model, metode dan bahan ajar yang tepat dan memadai agar pembelajaran dapat berjalan dengan lancar. Hal ini disebabkan banyaknya istilah ilmiah yang harus dipahami oleh mahasiswa, selain itu pada mata kuliah mikologi mahasiswa juga dituntut untuk benar-benar memahami konsep, ciri-ciri, macam-macam dan karakteristik dari keberagaman jamur makroskopis (Harlis \& Budiarti, 2017)

Berdasarkan hasil pengamatan selama mengajar mikologi, diketahui bahwa penggunaan model atau metode yang konvensional berupa ceramah sebatas pada penjelasan materi, diskusi, tanya jawab mengakibatkan banyak sekali mahasiswa yang kurang memahami materi yang diajarkan (Dewi, 2018). Selain itu dengan adanya perkuliahan yang monoton akan membuat mahasiswa menjadi bosan dan mengabaikan penjelasan materi yang disampaikan oleh dosen. Permasalahan tersebut akhirnya berdampak pada keaktifan mahasiswa dalam berdiskusi menjadi rendah. Rendahnya kemampuan berdiskusi mahasiswa akan mempengaruhi jalannya proses perkuliahan dan perkuliahan menjadi tidak efektif (Mulyadi \& Diana, 2018). upaya untuk mengatasi ketidakaktifan mahasiswa dalam perkuliahan, maka perlu adanya model pembelajaran yang menarik, inovatif dan membuat mahasiswa penasaran terhadap materi yang diajarkan dalam perkuliahan tersebut (Ariyanto \& Huda, 2013). Salah satu model pembelajaran yang dianggap mampu menumbuhkan keaktifan mahasiswa adalah Read Question Answer (Mulyadi \& Diana, 2018).

Read Question Answer (RQA) merupakan salah satu bentuk model pembelajaran yang memiliki tiga tahap sesuai kepanjangannya yaitu membaca, bertanya dan menjawab (Mulyadi \& Diana, 2018). Model pembelajaran ini awalnya dikembangkan oleh Corebima (2009), pidato pengukuhan Guru Besar beliau mengemukakan bahwa pada pembelajaran RQA, mahasiswa memang dituntut untuk serius dalam membaca dan memahami isi bacaan, selanjutnya berupaya menemukan isi bacaan yang susbtansial yang nantinya akan dibuat suatu pertanyaan. Pertanyaan tersebutlah yang nantinya diharapkan akan meningkatkan keaktifan mahasiswa dalam berdiskusi. Hal yang melatar belakangi pengembangan model RQA adalah banyaknya kasus ketidakaktifan siswa selama melaksanakan proses pembelajaran dikarenakan siswa kurang bahkan tidak mau sama sekali membaca materi yang diajarkan pada hari itu. Selain siswa menjadi tidak aktif, daya kemauan siswa untuk membaca akhirnya 
menjadi rendah. Dengan adanya permasalahan tersebut mengakibatkan pembelajaran tidak dapat berjalan sebagaimana mestinya (Corebima, 2009). Keunggulan model RQA ini adalah tiap tahapnya mendorong mahasiswa untuk aktif membaca dalam mencari berbagai informasi terkait materi yang akan dirangkum, dengan demikian mahasiswa akan paham dengan materi yang nantinya akan dipelajari. Pemahaman inilah yang akan menstimulasi mahasiswa untuk dapat memunculkan petanyaan-pertanyaan seputar materi. Penggunaan model RQA diharapkan nantinya dapat meningkatkan keaktifan mahasiswa dalam perkuliahan (Lashari et al., 2018). Pada penelitian Mulyadi \& Diana (2018) diketahuai bahwa tingkat kemampuan komunikasi yang rendah akan mempengaruhi jalannya diskusi yang dilakukan selama perkuliahan berlangsung. Kemampuan komukasi yang rendah dapat disebabkan oleh tingkat pemahamam mahasiswa terhadap materi yang dipelajari juga rendah. Hal ini dikarenakan minat membaca yang rendah dikalangan mahasiwa, sehingga masalah tersebut dapat mempengaruhi jalannya proses diskusi dalam perkuliahan. Keaktifan selama proses perkuliahan akan mendukung tercapainya tujuan mata kuliah mikologi. Adanya mahasiswa yang aktif dalam berdiskusi dan melakukan tanya jawab akan meningkatkan pemahaman mahasiswa pada materi yang diajarkan. Berdsarkan hal tersebut maka tujuan penelitian ini adalah mengetahui pengaruh penggunaan model RQA terhadap keaktifan mahasiswa dalam berdiskusi pada mata kuliah mikologi.

\section{METODE PENELITIAN}

Penelitian ini menggunakan metode kuantitatif dengan jenis penelitian quasi eksperiment. Desain penelitian, yaitu menggunakan one group pretest-posttest (Sugiyono, 2016). Desain penelitian one group pretest-posttest yang digunakan disajikan pada Tabel 1.

Tabel 1. Desain Penelitian One Group Pretest-Posttest

\begin{tabular}{cccc}
\hline Kelas & Pretes & Perlakuan & Postes \\
\hline A & 01 & A1 & 02 \\
\hline
\end{tabular}

Keterangan:

A : Kelas perlakuan

01 : Nilai pretes (nilai keaktifan mahasiswa sebelum pembelajaran dengan model RQA)

A1 : Model pembelajaran dengan model RQA

$\mathrm{O} 2$ : Nilai postes (nilai keaktifan mahasiswa setelah pembelajaran dengan model RQA)

Penelitian ini terdiri atas tiga tahapan. Tahap pertama, persiapan dengan mempersiapkan semua instrument yang digunakan dalam tahap pelaksanaan. Tahap kedua, pelaksanaan dengan menggunakan model RQA pada materi morfologi fungi, klasifikasi fungi dan reproduksi fungi. Tahap ketiga, pengolahan data menganalisis hasil angket untuk mendapatkan suatu hasil penelitian. Wiguna (2017) menjelaskan bahwa tahapan model RQA terdiri atas membaca (read) dimana seminggu sebelum jadwal perkuliahan, dosen menugaskan mahasiswa untuk membaca materi yang akan dipelajari pada pertemuan mendatang. Setelah membaca, mahasiswa wajib merangkumnya dalam bentuk power point serta wajib membuat dua pertanyaan dan dua jawaban dari pertanyaan tersebut sesuai materi yang dibahas (question). Pada saat jadwal perkuliahan, dosen akan menunjuk salah satu mahasiswa untuk mempresentasikan hasil rangkumannya yang sudah dibuat ppt, jadi tiap individu dalam setiap pertemuan siap presentasi jika ditunjuk oleh dosen (answer). Selama proses presentasi berlangsung dosen dan tim menilai keaktifan mahasiswa dalam berdiskusi sampai proses perkuliahan selesai. Tujuan menjawab pertanyaan ini adalah untuk mengukur pemahaman mahasiswa terhadap materi yang sudah dibawa dimana nanti akan disesuaikan dengan jawaban dari para teman sejawat 
saat berdiskusi jika pertanyaannnya tadi digunakan untuk bertanya dalam sesi diskusi (Hidayahtika et al., 2020).

Penelitian dilaksanakan pada bulan September s.d Oktober 2018. Pelaksanaan penelitian pada Program Studi Biologi Universitas Nusantara PGRI Kediri. Sampel dalam penelitian ini adalah mahasiswa semester 3 Program Studi Biologi sejumlah 12 orang mahasiswa yang sedang menempuh mata kuliah mikologi. Penelitian ini menggunakan satu kelas saja dikarenakan pada mahasiswa semester 3 Program Studi Biologi hanya ada satu kelas saja. Jika terdapat keterbatasan sampel penelitian, maka dapat memakai satu kelas sebagai populasi dan sampel. Teknik pengumpulan data menggunakan angket pengamatan keaktifan mahasiswa selama presentasi dan berdiskusi yang diberikan sebelum dan sesudah penggunaan model RQA. Terdapat lima indikator keaktifan yang dinilai selama diskusi pada perkuliahan mikologi, yaitu (1) memperhatikan presentasi dan diskusi dengan seksama, (2) tidak menyela saat presentasi berlangsung, (3) bertanya dengan baik dan sesuai materi diskusi, (4) mampu memberikan sanggahan atau membantu membenarkan jawaban, dan (5) menghargai jawaban, saran, atau sanggahan (Mulyadi et al., 2018).

Instrumen dalam penelitian ini adalah angket keaktifan mahasiswa yang diisi oleh observer pada saat pelaksanaan perkuliahan mikologi. Tim peneliti membantu dosen peneliti untuk menilai aspek keaktifan mahasiswa sesuai angket keaktifan yang dibuat. Setiap indikator dalam angket keaktifan mahasiswa memiliki rentang nilai, yaitu 1-3 dinilai kurang aktif, 4-5 cukup aktif, 6-8 aktif, dan 9-10 sangat aktif. Data penelitian berupa nilai rata-rata keaktifan mahasiswa. Data pada setiap indikator akan dijumlah dan dihitung rata-ratanya. Hasil rata-rata setiap indikator akan disesuaikan dengan tabel kriteria nilai keaktifan mahasiswa untuk menentukan tingkat keaktifan setiap indikator. Kriteria nilai keaktifan mahasiswa dapat dilihat pada Tabel 2. Data yang didapat setelah perlakuan akan diolah secara kuantitatif dimana semua data hasil pengamatan akan dihitung menggunakan angka-angka untuk menguji hipotesis yang telah ditetapkan (Sugiyono, 2016). Teknik analisis data menggunakan dependent paired sampel t-test dengan taraf signifikasi sebesar $0,05 \%$ untuk mengetahui pengaruh model RQA terhadap keaktifan mahasiswa dalam berdiskusi pada mata kuliah mikologi.

Tabel 2. Kriteria Nilai Keaktifan Mahasiswa

\begin{tabular}{cc}
\hline Rentang Nilai Keaktifan & Kategori \\
\hline $90-100$ & Sangat Aktif \\
$79-89$ & Aktif \\
$59-69$ & Cukup Aktif \\
$39-49$ & Kurang Aktif \\
$0-29$ & Tidak ada partisipasi \\
\hline
\end{tabular}

Sumber: Mulyadi \& Diana (2018)

\section{HASIL PENELITIAN DAN PEMBAHASAN}

Nilai rata-rata setiap indikator keaktifan mahasiswa dalam berdiskusi pada mata kuliah mikologi setelah menggunakan model RQA disajikan pada Gambar 1. Hasil analisis data keaktifan mahasiswa dalam berdiskusi pada perkuliahan mikologi dengan menggunakan dependent paired sampel $t$-test disajikan pada Tabel 3.

Tabel 3. Hasil Analisis Data Keaktifan Mahasiswa dalam Berdiskusi dengan Dependent Paired Sampel t-Test

\begin{tabular}{ccc}
\hline Data & Pretes & Postes \\
\hline Mean & 24,27 & 37,00 \\
Variance & 82,62 & 16,40 \\
\hline
\end{tabular}




\begin{tabular}{ccc}
\hline Data & Pretes & Postes \\
\hline Observations & 11,00 & 11,00 \\
Pearson Correlation & 0,87 & \\
Hypothesized Mean Difference & 0,00 & \\
$d f$ & 10,00 & \\
$t$ Stat & 7,15 & \\
$P(T<=t)$ one-tail & 0,00 & \\
$t$ Critical one-tail & 1,81 & \\
$P(T<=t)$ two-tail & 0,00 & \\
$t$ Critical two-tail & 2,23 & \\
\hline
\end{tabular}

Berdasarkan Tabel 3 di atas, diketahui bahwa t-hitung $(7,15)$ lebih besar dari t-tabel $(2,23)$ yang berarti $\mathrm{H}_{0}$ ditolak dan $\mathrm{H}_{1}$ diterima. Hal ini menunjukkan bahwa penggunaan model RQA memiliki pengaruh yang signifikan terhadap keaktifan mahasiswa dalam berdiskusi pada mata kuliah mikologi.

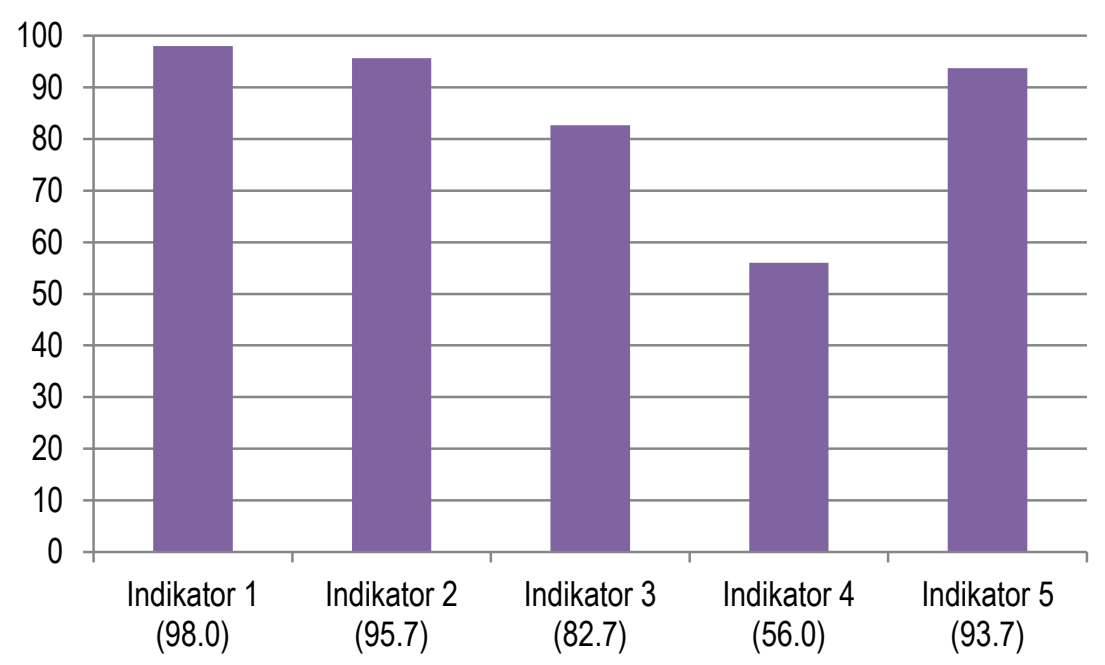

Gambar 1. Nilai Rata-rata Setiap Indikator Keaktifan Mahasiswa dalam Berdiskusi

Gambar 1 menjelaskan bahwa indikator 1 yang menunjukkan aspek presentasi dan diskusi dengan seksama mendapatkan rata-rata sebesar 98,0 yang dapat dikategorikan sangat aktif. Pada saat pelaksanaan, para mahasiswa yang sudah siap dengan materi hasil rangkuman masing-masing. Materi tersebut sudah dibuat dalam bentuk power point. Hal ini menandakan bahwa pada tahap read (membaca) pada RQA sudah diterapkan. Begitu juga dengan penyajian pertanyaan dan jawaban yang sudah dibuat oleh masing-masing mahasiswa. Pertanyaan yang telah dibuat nantinya bisa diajukan dalam proses diskusi dan tanya jawab. Tahap read (membaca) akan mendorong mahasiswa dalam memahami isi materi yang disajikan pada tiap pertemuan (Lashari et al., 2018). Tahap read ini mestimulasi mahasiswa untuk mencari segala informasi terkait materi yang akan dibahas melalui membaca. Aktivitas membaca diharapkan mampu memudahkan penyampaian segala informasi yang lebih mudah dipahami. Ketika mahasiswa memahami materi yang akan dibahas, maka mahasiswa akan lebih siap dalam mengikuti perkuliahan, sehingga dapat mengikuti seluruh tahap dalam proses perkuliahan dengan baik (Ramdiah \& Adawiyah, 2018).

Pada indikator 2 yakni tidak menyela saat presentasi berlangsung memperoleh rata-rata sebesar 95,7 dan masuk dalam kategori sangat aktif. Hal ini menandakan sebagian besar mahasiswa 
memperhatikan presentasi yang disajikan oleh temannya dengan baik. Apabila ada hal yang kurang dipahami atau ada yang ingin ditanyakan akan disimpan sampai sesi diskusi dibuka oleh penyaji. Selanjutnya pada indikator 3 yakni bertanya dengan baik dan sesuai materi diskusi mendapatkan ratarata sebesar 82,7 dan masuk kategori aktif. Selama proses diskusi berlangsung terlihat sekitar 3-6 mahasiswa yang aktif bertanya. Pertanyaan yang telah dibuat bisa diajukan pada proses tanya jawab dalam diskusi. Pertanyaan sebelumnya sudah dipersiapkan agar jalannya diskusi tidak keluar dari materi yang dibahas (Hidayahtika et al., 2020).

Pada indikator 4 yakni mampu memberikan sanggahan atau membantu membenarkan jawaban mendapatkan rata-rata 56,0 dan masuk kategori cukup aktif. Hal ini menandakan bahwa mahasiswa mulai terbiasa mengajukan pertanyaan, namun untuk memberikan sanggahan atau memberikan saran pembenaran terhadap jawaban pertanyaan masih rendah. Mahasiswa yang mampu melakukan indikator 4 hanya sekitar 3-4 mahasiswa saja. Rendahnya kemampuan pada indikator 4 disebabkan mahasiswa yang merasa kurang percaya diri ketika ingin menyanggah. Selain itu mahasiswa juga merasa ragu dan takut jika sanggahannya itu tidak tepat. Hal ini bisa dipicu karena kurangnya referensi yang dibaca oleh mahasiswa. Mahasiswa memahami materi hanya dari satu referensi saja, namun tidak mengeksplore referensi lebih banyak lagi untuk lebih memperkuat pemahamannya. Penggunaan model RQA ini membantu meningkatkan minat membaca mahasiswa dengan menggali dari berbagai sumber, agar informasi yang didapat memang benar-benar relevan dengan materi yang dibahas (Hayu, 2017).

Terakhir adalah indikator 5 yakni menghargai jawaban, saran, atau sanggahan mendapatkan rata-rata sebesar 93,7 dan masuk dalam kategori sangat aktif. Hal ini menandakan bahwa sebagian besar mahasiswa mampu menerima dengan baik dan menghargai setiap jawaban dari penyaji, saran atau sanggahan dari mahasiswa yang lain, sehingga diskusi dapat berjalan dengan baik. Adanya sikap saling menghargai antar mahasiswa dapat membuat penyaji merasa nyaman dan percaya diri saat mempresentasikan hasil rangkumannya dan menjawab setiap pertanyaan dari mahasiswa lainnya (Mulyadi \& Diana, 2018).

Berdasarkan uji $t$ dan rata-rata yang didapat dari setiap aspek terlihat bahwa penggunaan model RQA mampu meningkatkan keaktifan mahasiswa. Penggunaan model RQA dapat meningkatkan keaktifan mahasiswa berdasarkan penilaian tiap indikator keaktifan yang disajikan (Mulyadi \& Diana, 2018). Model RQA mampu menstimulasi mahasiswa untuk meningkatkan minat membaca, guna mencari berbagai macam informasi terkait materi yang dipelajari dari berbagai literatur (Wang et al., 2019). Minat membaca memang harus terus menerus distimulasi agar keinginan untuk mencari informasi melalui membaca semakin tinggi (Heth \& Lavidor, 2015). Penggunaan model RQA merupakan salah satu alternatif solusi untuk membantu mahasiswa beradaptasi dan mampu membangkitkan keterampilan membaca. Keterampilan membaca sangat penting dalam proses pembelajaran. Keterampilan membaca mampu meningkatkan wawasan yang dimiliki oleh mahasiswa, sehingga wawasan yang didapat mampu mendukung proses pembelajaran mahasiswa (Guthrie et al., 2009). Ketika mahasiswa memahami isi materi yang disampaikan maka transfer ilmu antara dosen dan mahasiswa akan berjalan dengan baik (Sudin et al., 2018). Begitu juga dengan kemampuan mahasiswa dalam mengajukan pertanyaan, menjawab pertanyaan, memberikan saran serta tanggapan sangat mempengaruhi jalannya diskusi. Model RQA dapat membuat mahasiswa belajar menyusun sebuah pertanyaan, sehingga pertanyaan tersebut dapat diajukan dalam proses diskusi (Darussyamsu et al., 2017). Selain itu pemahaman mahasiswa terhadap materi yang disajikan dapat meningkatkan 
kemampuan dalam memberikan sanggahan dan tanggapan terhadap jawaban yang dirasa kurang tepat (Murni, 2018).

Hasil dalam penelitian ini menunjukkan bahwa penggunaan model RQA sangat efektif untuk meninggkatkan keaktifan mahasiswa dalam berdiskusi. Sebelumnya memang banyak penelitian mengenai model RQA, namun hanya mengarah pada hasil belajar dan efektivitasnya saja. Merujuk pada penelitian sebelumnya yang dilakukan oleh (Mulyadi \& Diana, 2018) yakni meningkatkan keaktifan mahasiswa melalui model RQA, peneliti bermaksud ingin meneliti lebih dalam mengenai penggunaan model RQA pada mata kuliah yang berbeda dan dengan mengembangkan indikator penilaian yang berbeda yang disesuaikan dengan kondisi mahasiswa di tempat peneliti mengajar. Langkah-langkah (sintaks) pada model RQA inimenuntut mahasiswa untuk mengerti dan memahami isi materi perkuliahan yang akan datang melalui membaca, membuat poertanyaan dan menjawab pertanyaan itu sendiri (Maulida \& Mayasari, 2019). Kemampuan dalam memahami materi perkuliahan akan berpengaruh terhadap kesiapan dan keaktifan mahasiswa dalam mengikuti sesi diskusi dalam perkuliahan. Kesiapan tersebut diharapkan mampu meningkatkan keaktifan mahasiswa tidak hanya dalam mata kuliah mikologi namun bisa juga pada mata kuliah yang lainnya. Pada akhirnya minat membaca, kesiapan dalam perkuliahan, kemampuan berkomunikasi dan keaaktifan dalam berdiskusi dapat dimiliki oleh masing-masing mahasiswa (Maulida \& Mayasari, 2019).

\section{SIMPULAN}

Ada pengaruh penggunaan model RQA terhadap keaktifan mahasiswa dalam berdiskusi pada mata kuliah mikologi dengan nilai t-hitung lebih besar dari t-tabel $(7,15>2,23)$. Keaktifan mahasiswa dalam berdiskusi pada mata kuliah mikologi mengalami peningkatan setelah penggunaan model RQA. Selanjutnya, hasil penelitian ini dapat dijadikan sebagai rujukan untuk penelitian lebih lanjut tentang penggunaan model RQA pada aspek keterampilan berpikir tingkat tinggi.

\section{UCAPAN TERIMA KASIH}

Terima kasih kepada para tim sesama dosen yang turut membantu dalam penelitian ini. Para mahasiswa yang mampu beradaptasi dengan penggunaan model RQA ini, serta pihak-pihak lain yang tidak dapat saya sebutkan satu persatu. Semoga dengan adanya penelitian ini dapat menginspirasi para peneliti untuk melakukan penelitian lain yang sebidang dan mampu mengembangkannya lebih lanjut.

\section{RUJUKAN}

Ariyanto, R. R., \& Huda, M. (2013). Model-Model Pengajaran dan Pembelajaran : Isu-Isu Metodis dan Paradigmatis. In Yogyakarta: Pustaka Pelajar.

Corebima, A. D. (2009). Pengalaman Berupaya Menjadi Guru Profesional. Pidato Pengukuhan Menjadi Guru Besar dalam Bidang Genetika FMIPA Universitas Negeri Malang Disampaikan pada Sidang Terbuka Senat Universitas Negeri Malang Tanggal 30 Juli 2009. Retrieved from http://digilib.um.ac.id/images/stories/pidatogurubesar/gurubesar/Juni10/Pengalaman\%20Berupaya \%20menjadi\%20Guru\%20Profesional\%20-\%20Prof.\%20Dr.\%20Duran\%20Corebima\%20Aloysius $\% 202009 . p d f$

Darussyamsu, R., \& Fadilah, M. (2017). Pengaruh Strategi Pembelajaran Reading, Questioning and Answering terhadap Kemampuan Berpikir Kreatif Mahasiswa Jurusan Biologi FMIPA Universitas Negeri Padang pada Matakuliah Evolusi. Bioeducation Journal, 10(1), 2354-8363. Retrieved from http://ejournal.unp.ac.id/index.php/bioeducation/article/view/7086/5579 
Dewi, E. R. (2018). Metode Pembelajaran Modern dan Konvensional. Jurnal IImu Pendidikan Dan Pembelajaran, 2(1), 44. https://doi.org/10.26858/pembelajar.v2i1.5442

Guthrie, J. T., McRae, A., Coddington, C. S., Lutz Klauda, S., Wigfield, A., \& Barbosa, P. (2009). Impacts of Comprehensive Reading Instruction on Diverse Outcomes of Low- and High-Achieving Readers. Journal of Learning Disabilities, 42(3). https://doi.org/10.1177/0022219408331039

Harlis, H., \& Budiarti, R. S. (2017). Pengembangan Bahan Ajar Praktikum dan Instrumen Penilaian Berbasis Keterampilan Proses Sains pada Mata Kuliah Mikologi Program Studi Pendidikan Biologi Universitas Jambi. BIODIK, 3(2), 102-112. https://doi.org/10.22437/bio.v3i2.5501

Hayu, W. R. R. (2017). Strategi Umpan Balik Mahasiswa terhadap Perkuliahan Model Pembelajaran IPA SD Tahun Ajaran 2015/2016. Titian Ilmu: Jurnal IImiah Multi Sciences, 9(1), 18-22. https://doi.org/10.30599/jti.v9i1.77

Heth, I., \& Lavidor, M. (2015). Improved reading measures in adults with dyslexia following transcranial direct current stimulation treatment. Neuropsychologia, 70, 107-113. https://doi.org/10.1016/ j.neuropsychologia.2015.02.022

Hidayahtika, F., Suprapto, P. K., \& Hernawati, D. (2020). Keterampilan Literasi Sains Peserta Didik dengan Model Pembelajaran Reading, Questioning, and Answering (RQA) dalam Pembelajaran Biologi. Quagga: Jurnal Pendidikan Dan Biologi, 12(1), 69. https://doi.org/10.25134/ quagga.v12i1.2123

Irianto, K. (2014). Bakteriologi, Mikologi, Virologi Panduan Medis dan Klinis. In Bandung: CV. Alfabeta.2014. Alfabeta. Retrieved from http://cvalfabeta.com/product/bakteriologi-mikologi-danvirologi-panduan-medis-dan-klinis/

Lashari, D. A., Lisa, Y., \& Julung, H. (2018). Pengaruh Model Reading Questioning Answering (RQA) terhadap Pengetahuan Metakogitif Siswa pada Materi Sistem Pernapasan Manusia. JPBIO (Jurnal Pendidikan Biologi), 2(2), 27-33. https://doi.org/10.31932/jpbio.v2i2.222

Mahamod, Z., \& Mustapha, N. S. N. (2007). Strategi Pembelajaran Biologi di Kalangan Pelajar Sekolah Menengah. Jurnal Pendidikan Malaysia, 23, 153-175. Retrieved from http://journalarticle.ukm. my/198/1/1.pdf

Maulida, A., \& Mayasari, R. (2019). Pengaruh Model Pembelajaran Reading, Questioning and Answering (RQA) Terhadap Hasil Belajar Siswa Tentang Sistem Koordinasi Pada Manusia Kelas XI SMA di Kota Banjarmasin. Jurnal Pendidikan Hayati, 5(3), 99-106. Retrieved from https://www.jurnal.stkipbjm.ac.id/index.php/JPH/article/view/867/366

Mulyadi, \& Diana, E. (2018). Meningkatkan Keaktifan Mahasiswa dalam Berdiskusi melalui Model Pembelajaran Reading, Questioning, and Answering (RQA). Prosiding Seminar Nasional Biotik, 710-715. Retrieved from https://jurnal.ar-raniry.ac.id/index.php/PBiotik/article/view/4318/2854

Mulyadi, M., Adlim, A., \& Djufri, D. (2018). Memberdayakan Kemampuan Berpikir Mahasiswa Melalui Model Pembelajaran Reading Questioning and Answering (RQA). BIOTIK: Jurnal IImiah Biologi Teknologi Dan Kependidikan, 2(1), 33-37. https://doi.org/10.22373/biotik.v2i1.2511

Murni. (2018). Pengaruh Model Pembelajaran Reading Questioning and Answering (RQA) tentang Sistem Koordinasi pada Manusia terhadap Keterampilan Berpikir Kritis Siswa Kelas XI IPA SMA PGRI di Kota Banjarmasin. Jurnal Pendidikan Hayati, 4(3), 140-148. https://doi.org/10.1017/ CB09781107415324.004

Ramdiah, S., \& Adawiyah, R. (2018). Pengaruh Model Pembelajaran Reading Questioning and Answering (RQA) terhadap Hasil Belajar Kognitif Biologi Siswa Kemampuan Akademik Rendah. SIMBIOSA, 7(1), 1. https://doi.org/10.33373/sim-bio.v7i1.1255

Solikhah, I. (2015). KKNI dalam Kurikulum Berbasis Learning Outcomes. LINGUA: Journal of Language, Literature and Teaching, 12(1), 1-22. https://doi.org/10.30957/lingua.v12i1.68

Sudin, S., Duda, H. J., \& Supiandi, M. I. (2018). Pengaruh Model Reading Questioning Answering terhadap Kemampuan Berpikir Kritis Siswa pada Pokok Bahasan Sistem Pernapasan Manusia. JPBIO (Jurnal Pendidikan Biologi), 3(1), 1-8. https://doi.org/10.31932/jpbio.v3i1.260

Sugiyono. (2016). Metode Penelitian Kuantitatif, Kualitatif, dan R\&D. Alfabeta. 
Wang, L., Lee, H., \& Ju, D. Y. (2019). Impact of Digital Content on Young Children's Reading Interest and Concentration for Books. Behaviour and Information Technology, 38(1). https://doi.org/10.10 80/0144929X.2018.1502807

Wiguna, F. A. (2017). Pengaruh Metode Pemberian Tugas (Resitasi) terhadap Kemampuan Berpikir Kritis Siswa pada Mata Pelajaran PKN Kelas IV SDN Mojoroto Kota Kediri. Ibriez: Jurnal Kependidikan Dasar Islam Berbasis Sains, 2(1), 45-64. https://doi.org/10.21154/ibriez.v2i1.25 